Der

\title{
Stand unserer Kenntnisse vom fossilen Menschen
}

von

\section{Dr. Wilhelm Branca}

o. ö. Professor fär Geologie und Paltiontologie an der Universität Berlin Geheimer Bergrai

7weite, veränderte Ausgabe mit einem Nachtrage von

Dr. Hermann Stremme

u. Professor f. Mineral. u. Geologie a. d. Technischen

Hochschule in Danzig

Mit zahlreichen Abbildungen

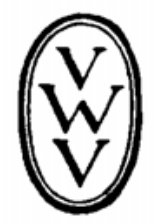

Berlin und Leipzig 1919

Vereinigung wissenschaftlicher Verleger

Walter de Gruyter \& Co.

vormals G. J. Göschen'sche Verlagshandlung :: J. Guttentag, Verlagsbuchhandlung :: Georg Reimer :: Karl J. Trübner :: Veit \& Comp. 
Alle Rechte, einschließlich des Übersetzungsrechts, vorbehalten.

Druck von Metzger \& Wittig in Leipzig. 